\title{
Danger explodes, space implodes: the evolution of the environmental discourse on nuclear waste, 1945-1969
}

Judi Pajo

\begin{abstract}
Background: The ways in which the public understands nuclear waste affect nuclear waste policy and the actual disposal of nuclear waste. This paper traces the origins and the evolution of the public understanding of nuclear waste through an analysis of a sample of the historical record of the public discourse on the topic.

Methods: This paper employs sociocultural anthropology methods innovatively: rather than emphasizing the data collection aspect of participant observation, it emphasizes interpretive discourse analysis, sampling the archives of the New York Times as a de facto ethnographic repository of the U.S. discourse on nuclear waste spanning the years 1945-1969.

Results: Whereas no evidence of a public concept for nuclear waste is found in the chronologically first item of this study's dataset, the chronologically last item implies a public conceptualization of nuclear waste that appears not too different from the one encountered today.

Conclusions: The paper illuminates especially the evolution of two key threads of environmental consciousness in the U.S. public discourse: as waste grew ever more harmful in the public understanding, the space available for disposing of it shrank and eventually disappeared.
\end{abstract}

Keywords: Nuclear waste disposal, Public discourse, Radioactive contamination, Environmental consciousness, New York Times

"[S] ome kind of national burying place will be needed.... It has been proposed ... to cast the atomic waste coffins in heavy concrete and lower them into one of the great deeps of the ocean or shoot them off the earth in a rocket that would become a satellite in outer space" [1].

\section{Background}

The problem of nuclear waste disposal

"America's nuclear waste management program is at an impasse" states the 2012 report submitted to the U.S. Secretary of Energy by the Blue Ribbon Commission on America's Nuclear Future ${ }^{1}$. Indeed, over 165 million pounds of high-level radioactive waste wait for permanent disposal in the U.S.; most is spent nuclear fuel from the energy industry ${ }^{2}$, and the rest originates from legacy

Correspondence: jpajo@pace.edu

Sociology/Anthropology Department, Dyson College, Pace University, 41 Park Row, Room 725, New York, NY 10038, USA national defense activities and from the navy ${ }^{3}$. While decay requires tens of thousands of years ${ }^{4}$, the temporary arrangements under which the bulk of this inventory is currently stored, at hundreds of locations dispersed throughout the U.S. ${ }^{5}$, were not designed for permanent storage and are not deemed safe for the permanent storage of high-level nuclear waste $^{6}$. Yet radioactive waste has been accumulating there ever since the nuclear energy industry took off in the 1950s and then grew in the 1960s. Some of the high-level nuclear waste currently under temporary storage dates as far back as the Second World War.

The last event of major significance in a decadelong and conflict-ridden journey towards a permanent disposal solution to the nation's nuclear waste problem was the halting of work on the targeted site at Yucca Mountain in Nevada in 2008. The Blue Ribbon Commission (BRC) characterized this as "the latest indicator of a [nuclear 
waste management] policy that has been troubled for decades and has now all but completely broken down" [2]. There is little dispute that the key reason underlying nuclear waste's unfolding complex story of "controversy, litigation, and protracted delay" lies with grave public concerns over "adequate protection of public health and safety and the environment" [2]. The BRC assesses that "finding sites where all affected [...] are willing to support or at least accept a [permanent nuclear waste storage] facility has proved exceptionally difficult" [2]. Put in other words, the U.S. public, in virtual unanimity, views nuclear waste as hazardous to human health and to the natural environment and does not deem safe any of the known methods for disposing of it.

Yet inability to reach agreement about a site of permanent disposal does not make nuclear waste disappear. In fact, the U.S. inventory of nuclear waste continues to grow: some four to five million pounds of high-level radioactive waste are generated by the nuclear energy industry annually ${ }^{7}$. Piling up nuclear waste in temporary storage facilities poses as great, if not greater, threats to the natural environment, to public health, and to national security as does disposing of such waste under permanent arrangements. In addition, the current impasse threatens the viability of a significant source of energy, making visible one aspect of the complex body of obstacles that the development of non-carbon sources of energy needs to overcome: at present, nuclear power supplies around one fifth of the electricity in the U.S.; with the caveats of solving accident vulnerability and waste disposal issues, nuclear energy may represent an alternative to the continuing global rise in carbon emissions.

\section{The public conceptualization of nuclear waste}

At present, the opposition to hosting a nuclear disposal site usually appears to be considered a given. Yet a range of explanations coexist as to the origins of the public conceptualization of nuclear waste ${ }^{8}$.

One common and seemingly commonsensical suggestion is that today's public concerns over the safety of nuclear waste disposal started with the popular political movements of the 1960s and 1970s. These movements have been historically well documented [3] and continue to draw significant scholarly interest into the present [4, 5]. At the same time, they are also generally viewed as springing out of certain remarkable deeds of some remarkable individuals. The biologist and social critic Rachel Carson, for example, is often credited with having "laid the foundation for the modern environmental movement" [6]. "Senator Gaylord Nelson created Earth Day as a way to force this issue onto the national agenda," reads a page from the website of the Environmental Protection Agency; "Twenty million Americans demonstrated in different U.S. cities, and it worked!" [7].
Another line of argument specifically relates the American public's negative perception of all things nuclear to the history of nuclear weapons [8], including weapons testing 9 . This view focuses on the devastating aftermath of nuclear explosions as well as, in addition, on a series of visible individual accidents such as the most recent meltdown at Fukushima, Japan in the year 2011 [9].

In yet another portrayal, the cultural origins of "nuclear fear" may be rooted more profoundly in our shared myths if not even human consciousness. It is some kind of deep mythical fear, in other words, that is then stoked by both the imagery of nuclear warfare and the visibility of nuclear energy disasters such as the recent Fukushima meltdown or Chernobyl and Three Mile Island before it $[10,11]$.

Given that the public conceptualization of nuclear waste underlies the political impasse that in effect perpetuates the storage of radioactive waste under temporary arrangements and threatens the viability as well as future of a significant energy source, it may be instructive to inquire into it more closely. Where does the public conceptualization of nuclear waste really come from?

\section{Nuclear waste in public discourse}

To understand the public conceptualization of nuclear waste, this paper takes the route of empirical investigation, while recognizing that a number of routes are possible and promising ${ }^{10}$. It adapts key methodological tools from sociocultural anthropology to produce a sample of the records of the U.S. public discourse on nuclear waste and then subjects that sample of records to interpretive discourse analysis.

The records in the dataset produced for the study span the years 1945-1969, the timeframe corresponding to what this researcher earlier identified as the first wave of public discourse on nuclear waste ${ }^{11}$. The core reason for limiting the investigation to this timeframe has to do with the emergence and the shaping of the notion of nuclear waste in public discourse. Regarding starting at 1945, as discussed in the researcher's earlier study, there is no evidence of a notion of nuclear or atomic or radioactive waste in the public discourse prior to that year. Regarding the 1969 cutoff, the researcher's earlier study also indicated that, by the time President Nixon took office in early 1969, the concept of nuclear waste in the public discourse had already assumed the familiar shape in which it is encountered today: the second wave of public discourse characterized nuclear waste primarily in terms of its threats, dissociated from the benefits of nuclear exploitation, and as carrying risks that cannot be eliminated. 


\section{Methods \\ Designing an anthropological lens to look at public discourse on nuclear waste}

To trace the evolution of the environmental consciousness on nuclear waste in the U.S., this paper employs the research and analytical methods of sociocultural anthropology. The methodology is fitting to the task for anthropologists have honed their research to the very aims of mapping out and understanding what at various points in the discipline's history has been seen as cultural structure, grammar of culture, cultural meaning, or simply culture.

Yet it is not possible to conventionally employ the ethnographic toolkit for meaningfully studying the environmental consciousness on nuclear waste in the U.S. The key reason lies with the method of participant observation, which within the discipline of sociocultural anthropology is widely considered to be the vital core of ethnographic research. In its conventional application, ethnographic participant observation requires the researcher personally to take part, indeed to immerse her own self, in most facets of human activity in the setting that she investigates. But a researcher cannot travel back in time to the U.S. of the years 1945-1969 when the environmental consciousness regarding nuclear waste took shape. Neither can a researcher personally participate in the range of human activities that take place in a setting the size of the U.S., at least not in the same way that she can participate in the lives of the people on a small island.

The methodology of ethnographic participant observation was originally developed for making sense of cultures that appeared rather entirely alien when encountered by the West, cultures of peoples not known to "us," cultures "without history," or, in better words, cultures that were encountered in the absence of a written record of documentation recognizable in the West [12]. Indeed, many an ethnographic project traditionally started with the researcher's learning of a native tongue. In contrast, this study's object of focus is far from alien and has been extensively documented. An abundance of textual and audio-visual records of what was said about nuclear waste disposal in the U.S. between 1945 and 1969 can be found across numerous physical libraries, archives, and electronic databases: news reporting and commentaries across a range of media outlets, as well as innumerable governmental reports and scholarly studies, not to mention popular literature across different nonfictional and fictional genres as well as works of visual art and moving pictures.

In order to design an anthropological lens that could be useful for looking at the evolution of environmental consciousness on nuclear waste in the U.S., this researcher interpreted the core of ethnographic participant observation to lie not with personal immersion in the life of a community bound to a physical setting but rather with the method's blending of rigorous empirical observation with a shifting of perspective from the observer to the subject of observation. Instead of emphasizing the convention of the data collection aspect of the participant observation method, the anthropological lens re-designed in this way focuses on identifying and sampling data that represent an equivalent to traditional ethnographic fieldnotes.

Such re-design yields the additional benefit of improving the scope of data under investigation. The emphasis that conventional anthropological research places on a researcher's personal immersion in fieldwork and on a holistic approach to observation clearly aims at broadening the body of empirical observations. In furtherance of the same direction, the painstaking documentation of the researcher's holistic observations in fieldnotes aims to produce as extensive a record of data for subsequent analysis and interpretation as possible. Nevertheless, the researcher's personal participation in the collection of data necessarily limits the scope of such data strictly to what one individual can produce within exacting frames of time. Even in the best of implementations of participant observation, the voluminous fieldnotes and records produced through ethnographic research represent narrowly limited data samples.

In contrast, this study's empirical focus, the body of the environmental discourse on nuclear waste in the U.S., challenges the researcher not with the production of ever more data. Rather, the challenge is how to sample the multiple and rich sources of records in a way that the dataset produced, while representative, and while holistic in scope so that potentially significant findings are not hindered by exclusion of potentially significant variables from the start, would also meaningfully lend itself to qualitative analysis and in-depth interpretation in the best of the anthropological tradition.

\section{Sampling environmental discourse in the archive of the New York Times}

The challenge was resolved with identification of the archive of the New York Times as the source for sampling the environmental discourse on nuclear waste between the years 1945 and 1969.

Given this timeframe, a newspaper archive is an especially appropriate source from which to draw a dataset that would address a question such as where the concept of nuclear waste disposal comes from. Arguably, the extent to which newspapers reflect the public discourse and influence the public discourse is commensurate with at least the extent to which their physical printed copies reach into the hands of readers ${ }^{12}$. This study's timeframe appears to have also been the heyday of newspapers in 
America: their circulation grew steadily after the Second World War and it was not until the 1970s that newspaper circulation fell below the number of U.S. households $[13,14]$.

Among the large body of U.S. media outlets, the New York Times stands out for its sizable national circulation as well as for its editorial ambitions of covering "All the News That's Fit to Print." During the timeframe that is the focus of this study, the pages of the New York Times recorded the voices of a great number of individuals: not only reporters and editors but also readers whose published addresses and feedback to the newspaper regarding what they read in its pages and what they perceived to happen in the world around them, though editorially controlled, represent a sampling of voices from a substantial pool. So the New York Times is best positioned also for serving as a proxy for the knowledgeable and articulate individual that conventional ethnographic research designates as "key informant". Throughout the years under investigation, the New York Times pursued the role of the nation's "newspaper of record," and, arguably, it accordingly influenced numerous other media organizations throughout the nation. This special standing is highlighted by a fact of symbolic pertinence to this study: it was a reporter of the New York Times, William L. Laurence, who the U.S. government drafted in 1945 to write the official history of the atomic bomb project.

Regarding the technical aspects of sample selection, the records that constitute the dataset used for the analyses and interpretations outlined in the following pages were drawn from the electronic archives of the New York Times through keyword searches: they were selected for containing in their headings and/or subheadings one of the keywords "atomic," "radioactive," or "nuclear" in combination with the keyword "waste," and they were all published between the years 1945 and $1969^{13}$. The electronic archives characterize these items as "articles," "front page articles," "editorials," and "letters to the editor."

The dataset contains 73 records in total ${ }^{14}$. Placed in a historical chronology, 17 of these items correspond to the presidency of Harry Truman, 1945-1953; 44 to the presidency of Dwight Eisenhower, 1953-1961; 6 to the presidency of John F. Kennedy, 1961-1963; and 6 to the presidency of Lyndon B. Johnson, 1963-1969. There is some significance to the fact that the vast majority of these records correspond to the Eisenhower presidency: while President Truman and President Eisenhower each served the same amount of time in office, the New York Times published well over twice as many items fitting this study's sampling criteria during the Eisenhower presidency. The rate of publication for such items then fell under President Kennedy and all but disappeared under President Johnson.

\section{Interpretive discourse analysis}

The findings outlined in the following pages were reached through subjecting this dataset to what may be called interpretive discourse analysis. Given the researcher's prior work with these discourse records as part of a larger dataset $^{11}$, the present analysis represents a re-visitation of the data that focused specifically on addressing the question of the conceptualization of nuclear waste. Specifically, the researcher freshly read each one of the items in the dataset, with which she was already familiar from previous readings and analyses, now literally to answer the question: How is nuclear waste conceptualized in this item? The answer to that question could be a direct quotation from the item, a paraphrase, or a verbalization of what appeared to be implied in specific discourse segments in the item. The last, an interpretation, counts for how the researcher most typically answered the research question at the conclusion of such re-reading of a dataset item. Oftentimes, the answer reached after visiting a record, or a tentative articulation of a finding, prompted yet another visitation of a previously visited record or even pool of records. The goal of such repeated interpretation was to unearth the meanings that underlay the literal level of discourse in a given record and that also permeated the larger sample of records. Focusing on the underlying shared meanings would have also helped counter for biases that would arguably be present in records that were editorially pre-selected. This analysis was less interested in the literal level of discursive statements possibly influenced by "for" or "against" editorial and/or political positions, and rather more interested in teasing out the shared underlying understandings that, regardless of the political position an individual had assumed or would eventually assume, defined the very topic of nuclear waste in the public discourse of the time under investigation. The quotations and illustrations in the following section are not exhaustive; other segments could be cited, and the entire dataset is available from the author upon request.

\section{Results}

A significant finding of this research concerns the evolution of the public conceptualization of nuclear waste during 1945-1969. Whereas no evidence of a public concept for nuclear waste is found in the chronologically first item of this study's dataset, the chronologically last item implies a public conceptualization of nuclear waste that appears not too different from the one encountered today. The interpretive analysis of the items in the study's sample identified four key conceptual stages in this evolution: in the first stage, nuclear waste was introduced to public discourse in a tentative definition; in the second, public discourse agnostically assessed nuclear waste; during the third stage, a view of nuclear 
waste crystallized; by the fourth, nuclear waste appeared to be resolutely defined.

An additional significant finding is that this process was shaped largely by the mutual evolution of two conceptual threads. The first is the hazard perspective: over the course of the years under investigation, nuclear waste was framed in the public discourse in terms of danger-increasingly and with increasing certainty. The second thread is the vanishing of physical space for safe disposal: as nuclear waste was ever more markedly understood in terms of threat to human health and to the natural environment, the space available for disposing of it came to be conceptualized as ever more limited and remote-until it eventually disappeared.

The following paragraphs periodize the evolution that brought the public conceptualization of nuclear waste into the shape in which it is encountered at present and also highlight some of the terms in which the hazard definition of nuclear waste and the shrinking of disposal space for it were articulated, in tandem, as they evolved.

\section{Discussion}

Periodizing the evolution of the public conceptualization of nuclear waste

Plotting the distribution of dataset items by year of publication reveals an approximate correspondence between the stages of conceptual evolution named above and the annual rates at which the sampled records of the public discourse on nuclear waste made the pages of the New York Times. Interestingly, at least three of the four stages through which the public conceptualization of nuclear waste evolved appear to correspond to nearly normal distributions with clear peaks. The first stage, which started in the year 1948 and continued through the year 1951, saw the peak in the rate of publication of items that fit the sampling criteria of this study sometime between the years 1949 and 1950. The records interpreted here as indicative of the second stage of evolution of public discourse on nuclear waste were published in the New York Times between the years 1953 and 1956; the rate of their publication peaked in the year 1955. The third stage, which can be placed within the years 1958 and 1963, reached the peak of publications in 1959. It may be slightly a stretch to view the years 1966 and 1967 as the flat peak of the period 1964-1969; more appropriately, the fourth stage of evolution may be viewed as corresponding in the distribution chart not to a curve but rather to a flat without a peak: indeed, the fourth stage represents the end of the evolution of the public concept of nuclear waste.

The entire sample's pinnacle of publication rate, reached in the year 1957, lends itself to two complementary views. In the first, the year 1957 marks the transition from the second to the third stage of conceptual evolution: the interpretive analysis reveals that it was essentially in this year that the public discourse re-oriented its focus from the earnest assessment of the potential dangers of nuclear waste to crystallizing the notion of nuclear waste as irredeemably dangerous. Complementing this watershed view, 1957 may also be seen as the peak of the 11-year timeframe 1952-1963, a longer stage of conceptual evolution, in this complementary view, that started with an agnostic assessment of nuclear waste and concluded with a crystallization of the public view of nuclear waste as irredeemably a threat.

\section{5 , before nuclear waste}

The first time that the notion of waste appears in proximity to the notion of atomic reaction in this dataset is in the remarkable firsthand account of the bombing of Nagasaki in 1945. William L. Laurence, the only reporter to be part of the military mission on August 9, subtitled his September 9 piece "A City Laid Waste by World's Most Destructive Force." The waste of nuclear, in other words, was the devastation that followed the explosion of the bomb. Deploying the "World's Most Destructive Force" had to do with putting an end to war. So the bomb was to be admired: "It is a thing of beauty to behold, this 'gadget.' It its design went millions of manhours of what is without doubt the most concentrated intellectual effort in history." Clearly, as of 1945, public discourse must not yet have indexed the connotations of nuclear that dominate public discourse today.

\section{Stage one, tentative definitions}

To the extent that the historical archive of the New York Times may serve as a proxy for a chronological record, "atomic waste" in the sense of "waste materials from atomic energy plants" was formally introduced to the U.S. public discourse on April 15, 1948. As discussed in this researcher's earlier study, this was the era of the science and technology paradigm of public discourse on nuclear waste ${ }^{11}$. Covering an expert conference session on "the peace-time problems of the disposal of radioactive waste" qualified as "the first on that subject ever incorporated in a general safety meeting," the report quotes government technocrats arguing for this "serious hazard of the future" to "be put on the same agenda with problems of hotel and restaurant safety, traffic, fire prevention and home accidents." Some effort, in other words, appears to have been deemed necessary to draw proper attention to the topic of atomic waste. But the war was over and peacetime was entitled to attend to its own challenges. The headline of the quoted record speaks of "safety menace" and further on the record relates that even though "sufficient dilution of some radioisotopes in water renders them presently harmless, it is questionable whether radioactive wastes can be made 
safe for disposal in a drainage system in the ocean merely by aqueous dilution."

Remarkably, the records from the years 1948 through 1951 indicate that the most significant terms in which nuclear waste would eventually come to be defined and is presently understood were introduced into the public discourse already in this first stage: the key notion of a potential hazard that is difficult for humans to sense yet may constitute a safety concern; the recognition that gradations in the level of radioactivity would correspond to gradations in the threat that radioactivity poses to human health; the notion that certain methods of disposal and certain places of disposal may amplify or mitigate that threat as well as carry different costs. Even the idea of one single national disposal site was already introduced in this stage. Titled "Atomic 'Cemetery' Needed for Waste," a report from July 29, 1950 argues that "some kind of national burying place will be needed for the lethal substances;" this would be superior to disposing of nuclear waste by dumping it in the ocean, conditional on a plausible scenario: "[i]f fish ate the material, scientists fear it might find its way into food used by humans." Clearly, a route for radioactive materials to enter the human food supply was already thought about.

Yet nuclear waste as well as the threats associated with it appear to have felt distant and abstract upon their initial introduction into public discourse-especially so when compared to how they would come to be articulated in the later stages through which the concept of nuclear waste evolved into the current public definition. At this first stage, the threat of nuclear waste was located persistently in a loosely specified future. For example, a report from February 13, 1949 that refers to information issued by the Atomic Energy Commission regarding land burial in containers comments that, though such disposal "may be good enough for the present," "the time will surely come when atomic power plants will be generating electricity and when it will be necessary to get rid of their radioactive wastes in a less cumbersome way."

"Cumbersome" is also a telling word: often in this first stage, the threat of nuclear waste seemed to be viewed as minor and dismissible; there was no dispute to the assumption that proper scientific and technological effort would make it disappear. Titled "Atomic Waste Dumped in Sea," a brief report of May 22, 1949 quotes the British Ministry of Supply at face value in explaining that nuclear waste dumped into sea was "only slightly radioactive and the amount too small to have any harmful effect on fish or on human life." On September 9, 1950, reporting on the success of laboratory experimenting that "may be a solution to the problem of getting rid of radioactive wastes from atomic research laboratories," a report optimistically titled "New Method Handles Radioactive Waste" concludes that "it is believed that [the experiments] would be applicable to larger plants, which might handle thousands of gallons of wastes daily." Better yet, a report from February 11, 1951 declares, in its title already, that "Dangerous Radioactive Wastes, Which Now Are Buried, May Have Many Industrial Uses." Of those "many" envisioned uses, the record specifies "the sterilization of food and pharmaceuticals."

Importantly, during this first stage of the evolution of the concept of nuclear waste in the public discourse, the space available for disposing of nuclear waste was envisioned as virtually unlimited. This is how a brief report of August 7, 1950 describes disposal at the Brookhaven National Laboratory in Long Island: "radioactive material [...] is collected in small tanks after it goes into the drains. If it 'cools off', it goes on into sewers. Any accidental seepage [...] can be detected quickly [...] Gas used to cool off the atomic pile is highly diluted before being released into the air." The water, the ground, and the air, indeed all of the planet must have been assumed to cache disposal possibilities.

All in all, as of 1951 nuclear waste was, in the words of two reports published that month, "a nuisance." And any of the multiple themes through which that nuisance was introduced into the public discourse seemed just as likely as any of the others eventually to dominate how public discourse would define nuclear waste: nuclear waste could turn out to become a matter primarily of threat and of danger just as much as it could turn out to become a matter of industrial cost efficiency just as much as it could turn out to become a matter of triumph of the scientific and technological effort over the wonders of the (manipulated) natural world.

\section{Stage two, focal points emerge}

Theme wise, the records from the year 1953 through the year 1956 have a mode: 6 out of the 14 touch on the theme of putting nuclear waste to one or another beneficial use. A triumphant headline of January 27, 1954, for example, announced that "Electricity Is Made From Atomic Waste." Penned by none other than the famed William L. Laurence, the report detailed at some length the technical backend of "[a]n atomic battery that converts atomic energy directly and simply into small but usable quantities of electrical energy." It was a genuine technological achievement, "[ $t$ ]his direct conversion for the first time in history of nuclear energy into electricity." To relate its significance, Laurence quotes David Sarnoff, head of the Radio Corporation of America and one of the most prominent industry figures of the time, to say that the technology underlying the prototype battery "may prove to be as significant as Edison's conversion of electricity into light." That the generation of electricity might have been among the most prominent of the potential uses of nuclear waste that were being 
pursued is supported by a brief record from May 18, 1955. Reporting on "a young Swiss student," just "18 years old," who had "designed a tiny self-powered electronic tube" that "would use built-in radioactive material from the atomic trash pile," the record noted that the achievement had won the student various prestigious accolades and concluded that it would eventually "assur[e] him a top college scholarship."

But electricity was not the only potential use that was envisioned for nuclear waste. Turning on its head, the potential military threat that the nuclear waste was sometimes seen to constitute, a record from May 20, 1954 entertained the idea that "the radioactive byproducts of atomic fission [...] have a potential military utility": they could be used to create "a lethal radioactive 'line' along a frontier, behind a river, across a peninsula, that would deny an area to the enemy." So it was with regret for the report to note that radioactive wastes were "too small in quantity today to irradiate anything but a small area." And it was with hope to conclude that "a large industrial complex dependent upon commercial atomic power would add daily significant amounts of radioactive waste products to the Nation's chemical armory."

The entertainment of scenarios such as a radioactive Maginot line, as well as the numerous technological pursuits of potential uses for nuclear waste, seems to have been manifestations of an overall effort to deny nuclear waste an existence as waste. That theme was articulated pithily in a record from May 8, 1956. Titled "Atomic Waste No Problem Yet, Strauss Says at Generator Site," the report cited the head of the U.S. Atomic Energy Commission while he, together with his British homologue, toured "this country's first full-scale atomic power project": Lewis L. "Strauss said the term 'atomic waste' is a misnomer".

Importantly, denying nuclear waste an existence as waste was not denial of the harms and hazards of radioactivity $^{15}$. On the contrary, the sample indicates that the danger presented by nuclear waste was submitted to public comprehension. For example, readers learned that, while the amount of nuclear waste in existence was relatively small, the anticipated expansion of the nuclear energy industry would expand it in the future.

Significantly, scientific delimitations of danger were given prominent attention. In a brief science note of June 26, 1955, an oceanographer opposed the dumping of nuclear waste in the ocean; the argument was that, over time, such practice "would have an unpredictable influence on the whole biological cycle of the sea." Some months later, on December 17, a substantive record spoke of scientific consensus on the point that "dispersal to the ocean cannot be the ultimate answer to radioactive waste disposal," on the grounds that, assuming dumping over five decades, "a highly radioactive form of strontium, known as Strontium 90, would be enough to contaminate 5 percent of the entire ocean volume." Readers were also to learn that "[i]n the body, strontium behaves much like calcium, with a specific affinity for bone, and is quite effective in producing bone cancer."

The key reference of the scientific delimitation of danger would indeed become human health. The second stage's most stern warning on "the biological effects of radiation" came on June 17, 1956. It was launched with the epic remark that "mankind must make up its mind whether a world movement for the control of atomic energy is to be organized or whether the human race must be slowly extinguished centuries hence." Singling out the "genetic dangers" posed by the radioactive byproducts of the energy industry, the record visualized "the perils that attend the peaceful uses of atomic energy" with "a four-leafed clover" and "a two-headed calf" and commented that a "legless animal has no chance of survival in the wilderness."

Such strong visual language notwithstanding, it would be incorrect to conclude that the second stage of evolution of the notion of nuclear waste in the public discourse concluded with a firm definition of nuclear waste as an irredeemable hazard. Indeed, a mere fortnight after the publication of the report quoted above, on July 1, 1956, one of the science notes carrying the initials of the very author of that article now reported on an achievement "in disposing safely of radioactive waste". But it is significant that, in this second stage, public discourse came to delimit the danger of radioactive waste in terms of science and with reference to human health.

It is also significant that the scientific consensus that had developed against ocean dumping put a crucial limitation to the space that, up until that point, was assumed available for the disposal of nuclear waste. No longer was there a public understanding of the planet as rife with possibilities for the disposal; the ocean was no longer to be used. Within less than 3 months from the first reporting of the oceanographer's argument against dumping came a revisitation of one earlier dumping report. Whereas on January 19, the New York Times had commented regarding the British dumping of 1500 tons of radioactive waste in the Atlantic Ocean that "[e]laborate precautions were taken to assure that the waste containers do not disintegrate until their contents have become harmless," on September 18 readers were reminded of "the consignment of 1,500 tons that was dropped into the sea last January" and were now to learn that "during the operation one container fell from a derrick with the result that the outer concrete casing broke." 


\section{7, shifting from seeking solutions to seeking protection}

This study's sample indicates that 1957 must have been a crucial year in the evolution of the notion of nuclear waste in the public discourse. That nuclear waste must have drawn intense interest is suggested even by the frequency of the coverage of the topic in the New York Times, the highest of the years 1945 through 1969. Indeed, revisiting the nuclear waste topic was common in 1957. For example, the inauguration of a research laboratory at a commercial petroleum company in Illinois that would "put to work" radioactive waste originated some 1500 miles away "from an atomic reactor in Idaho" was the theme of two consecutive records, on April 10 and April 14, 1957. Or, the conclusions of a report of the National Academy of Sciences regarding the safety of disposal procedures received coverage on May 1 and then again on May 5, 1957. Then in July, one case of dumping in the vicinities of New York City prompted three separate sampled records.

The three records of July 1957 also throw light on the shifting of focus that marks 1957 as the year in which public discourse moved from articulating nuclear waste in terms of multiple searches for utilization solutions to articulating it in terms of a pragmatic pursuit of protection from danger. On July 13, a brief record informed the readers that "a tanker carrying a load of radioactive sodium waste down the Hudson River en route to a dumping point 150 miles southeast of New York" was "expected to pass under the George Washington Bridge [on that same day of the reporting] and reach the Battery early at about noon." Nothing had yet happened, in other words, yet the fact that nuclear waste would be passing through common geographic points of reference clearly commanded attention. Then, on July 15, readers learned that an accident had befallen the shipment: "one of about twenty-five yellow, airtight receptacles dumped into the ocean" had "failed to sink." It was actual news this time, and the lengthier report announced it with alarm: "[a] steel container filled with radioactive sodium waste is floating somewhere in the Atlantic Ocean about 185 miles southeast of New York and is a 'menace to navigation." By the following day, July 16, the incident had also prompted "An Analysis of the Radioactive Waste Problem and Moves by U.S. to Meet It." This record designated the incident to be an illustration for "one of the increasing problems of the nuclear age" and argued for "most detailed precautions [...] to be taken about the disposal of radioactive waste materials; otherwise careless disposal procedures can be as damaging to a community as fall-out from a nuclear weapon." Despite its even greater length, the record spent one single sentence to relate that the lost container "was [...] later found."
The attention was justified neither by the shipment nor by the incident itself. It was remarkable for a shipment of just 25 nuclear waste containers of unspecified weight to be the topic of a report in the New York Times while uneventfully underway, especially in light of the fact that, as it would surface in a September 5 record that scrutinized the operations of a small company dedicated to the dumping of nuclear waste "somewhere at sea about twenty-seven miles off the Massachusetts coast," that one company had carried out more than 500 dumping trips by July 1957 and its capacities allowed for "more than 200 containers [to] be shipped to sea at a time." Moreover, while the incident of the one container failing to sink was announced with alarm, the lengthiest of the records related to the topic scattered only three words to relate that the lost container "was [...] later found."

The prompt for the extraordinary attention had to be something else. The sample indicates that it was a feeling of threat. That by 1957, nuclear waste must have been consensually perceived as threatening was already indicated in that year's earliest sampled record. The sole 1957 record to report on the success of yet another effort to channel nuclear waste into something of use, this time "a tiny atomic battery" that would power small devices "for almost limitless periods of time," the January 30 record addressed the safety issue already in its subtitle: "Device Using Waste of Reactor Is Called Safe as House Key."

But while the claim of the successful utilization appears to have been simply ignored, the safety issue continued its move towards the very center of public attention. On March 12, 1957, reporting on "the 1957 nuclear congress, supported by twenty-four scientific and engineering societies," the record zoomed in for "the dangers to the public from the spread of the atomic energy industry." Under the subtitle "Engineer Group Urges Plans by States to Control Wastes in Air and Streams From Nuclear Industry Plants" this record set the need for protection from the "long radioactive life of some of the wastes" into the "hundreds of years." This was a considerable augmentation of danger given that the highest previously cited number of radioactivity had been 33: a July 1, 1956 science note had explained that "Cessium has a half-life of thirty-three years, meaning that in thirty-three years it looses half of its radioactivity." By June 5, attention was focused on the "long range plans" of the U.S. Food and Drug Administration "to safeguard the country's future food supply against radioactivity." Headlined "U.S. Combatting Food Radiation," this record expressed the certainty of the "threat of radioactivity to food" in the words of a government official: "there is little doubt that a material amount of radioactivity will spill over into the farmland and water supplies of this nation."' 
So the government was already taking action; the record reported that "large-scale analyses to determine safe radiation tolerances were already under way."

Whereas the first record of the year 1957 reported on the search for a beneficial utilization of nuclear waste, the year's last record was about a different kind of technological pursuit: "the feasibility of injecting radioactive wastes into the ground without contaminating drinking water or creating other health hazards." So 1957 can also be seen as a watershed year: the search for utilization solutions was now the past; the future would be about protection from danger.

\section{Stage three, definition crystallized}

The records from the years 1958 through 1963 imply a crystallizing if not crystallized public definition of nuclear waste. Much of what took place with regard to nuclear waste between 1958 and 1963, as well as the ways in which that action was put into words, appear to spring from an understanding of nuclear waste as a grave danger.

The coverage of an occurrence in France in October 1960 is illustrative of how widely shared this understanding was. On October 11, the first of three consecutive records on the matter introduced the "intention" of the French Atomic Energy Commission "to sink 6,500 barrels of atomic waste in the sea between Antibes and Corsica Oct. 20" in terms of an international disagreement: "Prince Rainer III of Monaco wrote to President de Gaulle today to question the wisdom of a plan to dump radioactive waste in the Mediterranean." Then, the record went on to discuss the dynamics of "several protests from citizens on the French Riviera" and quoted one local official as saying "people here are legitimately alarmed" and as anticipating that "tourists would be afraid to swim in the Mediterranean." Minute details of the grassroots opposition to the dumping within the city of Nice, as well as an exchange between the city's mayor and the head of the French Atomic Energy Commission, were laid out in a record published on the next day, October 12, 1960. This second record highlighted "a rare manifestation of political unity" against the dumping: "Gaullist and Conservative City Councillors joined Communists in threatening to strike if the Government did not reconsider." The topic of a third item of coverage became the fact that the French government did reconsider. The record of October 13, 1960 speaks of "victory" that was "temporary" yet at the same time also "initial." This third record used the dismissive tone of the French atomic governing body to highlight the public understanding of nuclear waste as a threat: the agency's statement was quoted in referring to the anti-dumping campaigners as "persons who, lacking sufficient information, are currently expressing their fears." The record concluded by undermining that dismissiveness through lining the sovereign of Monaco up on the side of the anti-dumping campaign: "it was learned on good authority that Prince Rainer, now in Paris, has secretly visited President de Gaulle to express opposition to the dumping project."

That these public understandings of nuclear waste would have been shared this side of the Atlantic, is suggested by a record that was published on April 22, 1962. In reporting the decision of the Atomic Energy Commission to deny "a Houston company's application to dispose of low-level radioactive wastes in the Gulf of Mexico," the Associated Press cited an internal "finding" of the commission as ground for the action: "the granting of a license to dispose of packaged low-level radioactive waste in the Gulf of Mexico would have serious harmful effects on our friendly relations with Mexico."

The data indicate that this stage of the American public's understanding of nuclear waste was well recognized by elected representatives. Three records from these years specifically mention congressional or federal inquiries of one form of another: on March 18, 1958, upcoming "hearings on the disposal of industrial radioactive wastes" were reported in the New York Times; on June 28, 1959, readers learned that four federal agencies had requested a scientific investigation of "the problem of radioactive waste disposal into Atlantic and Gulf of Mexico coastal waters;" by September 3, 1959, "[a] joint Congressional subcommittee warned [that existing protection from radioactive waste] might run out as the peaceful use of the atom was expanded." To spell out the distinctions between high-level and low-level nuclear waste, this last record paraphrases the report presented to the U.S. Congress in explaining that "[h]igh-level waste could be more than a million times as dangerous to life and resources as low-level waste" and that "[h]igh-level waste is so dangerous that experts have not yet decided whether it would be safe to cast it 150 miles off shore into 1,000 fathoms of water $(6,000$ feet) and leave it there."

Nuclear waste would have been suspected as a cause of harm to the degree that incidents involving seemingly anything nuclear drew attention. An uneventful accidental leaking of "[a] small amount of radioactive material [...] from an exhaust stack at Oak Ridge National Laboratory" became news by the next day; the November 13, 1959 record informed that, despite the absence of "hazard to the public," employee cars "were washed, if necessary, to prevent spread of the material [...] in minute quantities." "Blasts in Boston Bring Atom Scare" reads the headline of a record from August 10, 1960 that reports on "three explosions [...] on an open pier about 200 feet from radioactive atomic waste; the fire authority declared "no fall-out danger" however, and the readers were additionally assured that " $t]$ he radioactive material 
on the pier was in thick concrete casks." A record of November 16, 1960 that reported the accidental death of a nuclear scientist at Shirley, Long Island "when a huge truck loaded with used atomic reactor fuel skidded on wet pavement and struck his car" must have felt the need to address the understanding of nuclear waste as danger already in its subheading: "Car Is Struck by Truck Full of Radioactive Waste-None Leaks or Spills."

By this stage of its evolution, public discourse on nuclear waste centered on getting rid of it. Whereas only 1 of the 25 records of this timeframe focused on the beneficial utilization of nuclear waste, the disposal theme was present in each one of the records. Indeed, even that one December 10, 1961 report on certain buoy "tests on the use of nuclear waste products as a source of electric power for lighted aids to [sea] navigation" touched on disposal in commenting that the tests were part of the broader search effort "by the A.E.C. for the use of waste atomic materials [that] are now buried as a rule for disposal."

The records overwhelmingly indicate that, in the public understanding, the space available for the disposal of radioactive waste had shrunk significantly. A brief Reuters news of April 9, 1958 reported on governmental efforts at the United Nations for "regulations to prevent pollution of the high seas or the air above" involved in radioactive waste disposal. Covering the study of a "panel of oceanographers" that was "asked to suggest disposal sites," a record from June 28, 1959 reported that "[a]fter intensive study of local oceanographic conditions, the panel selected twenty-eight possible disposal sites [that included] every major seaport area from Boston, Mass., to Corpus Christi, Tex." But on July 14, 1959, a record reporting on the finding by the National Science Foundation that "a fleet of 300 nuclear-powered ships could safely dispose low-level radioactive wastes in the oceans "without undue hazard to human health" concluded with a remark about the suggestion "that there were about twenty sites in the coastal waters of the Atlantic and Gulf of Mexico that could be used safely for the disposal of low-level radioactive wastes:" that suggestion had "drawn strenuous objections from some of the localities near the proposed dumping grounds."

The public sentiment of this stage might have been best captured in a sentence from a research report quoted in the New York Times on January 24, 1958: "[s]afe disposal means that the waste shall not come in contact with any living thing."

\section{Stage four, immune to denial}

The fourth and last stage of the evolution of the concept of nuclear waste in the U.S. public discourse is recorded in the dataset in a relative paucity of items: for all of the
6 years 1964-1969, there were only three records from the year 1966 and another three from the year 1967 that fit the study's sampling criteria; the other 4 years have no records in the dataset.

Though all six of the sampled records support the interpretation that the public concept of nuclear waste, which had already crystallized before 1964, was now growing immune to denials of danger, only one of them provides such support explicitly. For all the denials of the dangers of nuclear waste and for all the shunning of the topic of hazard in the five other records from this stage, the record of November 2, 1967 documents how the Maltese representative to the United Nations, one Dr. Arvid Pardo, gravely warned "that continued indiscriminate dumping of radioactive waste into the ocean might prevent man from utilizing the incalculable food and mineral resources of the sea bottom."

The other five records support the interpretation indirectly. They do so first of all by documenting the strategies of an underlying effort to quell what must have been perceived as a prevailing public understanding of nuclear waste as dangerous. One such strategy was avoidance of the topic of waste hazards. For example, two records concerning waste reprocessing and ocean dumping overseas, one from July 8, 1966 involving 13 European countries and the other from July 30, 1967 involving Japan, steered completely clear of the topic of danger. And on December 28, 1967, an item of Reuters news marked several months of delay in informing the readers of the previous summer's dumping in "the Eastern Atlantic" of "[e]leven thousand tons of solid radioactive waste." This one record also documented the denial strategy in action: it quoted the European Nuclear Energy Agency in giving assurance that the dumping would "represent no risk either to man or marine organisms."

Yet the most telling support for the interpretation that the public conceptualization of nuclear waste was now growing immune to denials of danger came from the manner in which such denials were sometimes articulated. A May 23, 1966 record, boldly titled "No Hazard Found in Atomic Wastes," opens with the case of one doctor who "can hardly abide the sight of whitefish, no matter how nicely prepared" because "for a year he has eaten a half pound of it every Friday, freshly caught downstream from the great atomic energy works at Hanford, Wash." The record hypothesizes, "[h]e probably carries the heaviest body burden of radioactive zinc of any man in history," yet "[h]e is not, however, in much danger. His burden of 'hot zinc' is still less than onetenth that considered permissible for the general public." But if nuclear waste was generally perceived as safe, why would anyone have needed to go through such an unusual symbolic experiment? 
The prompt for this report was an international symposium of the International Atomic Energy Agency in Europe which was then again covered on May 29, 1966. Not only does the second report recapitulate the case of the radioactively contaminated yet harmless fish, but it generalizes that the scientific evidence discussed at the symposium translated in "almost uniformly good" news: " $[t]$ here was no evidence that individuals in any part of the world had ingested enough of the debris to suffer harm, even by the most conservative health standards." And though admitting that "radioactivity seems sinister to the public" and that "[t]he idea of radioactive waste in food is alarming," this record denied the dangers of radioactivity with some striking sentences: "[e]very day [... w] ater drawn from the Columbia River to cool the great reactors at Hanford, Wash., is returned to the river with more than 60 different kinds of radioactive element. Those that survive the trip down the river are carried far out to sea, deposited on the ocean floor, or are picked up by oysters, clams, mussels and other creatures that delight the palates of those living in that region. Whenever residents of Chattanooga, Tenn., take a drink of water from the municipal supply, they imbibe a little bit of radioactive waste from Oak Ridge National Laboratory, far up the Tennessee and Clinch Rivers."

If not sarcastic, this bucolic depiction of the delights of radioactively contaminated victuals indicates at least that the understanding of nuclear waste as hazard was pervasive to the degree of prompting one to conceptualize its entering the human body. That even an explicit denial of danger cannot but reveal how profoundly the idea of danger ${ }^{16}$ was engaged suggests that the evolution of the concept of nuclear in the public discourse had been concluded.

\section{Conclusions}

It was after 1945 that public discourse in the U.S. wedded the notion of atomic with the notion of litter to denote the byproducts of the exploitation of nuclear reactions for energy production. And it was before 1969 that this new notion of nuclear waste was associated with devastating consequences to human health and to the natural environment to a point that, at present, puts a consensus for disposing of nuclear waste out of practical reach. When sampled and analyzed through an adaptation of anthropological methods, this critical period's record of the public discourse on nuclear waste suggests that the view of nuclear waste evolved over a number of conceptual stages-from an initial introduction as a byproduct that was suspected of potential distant threats, to an assessment of the nature of that threat, to a subsequent crystallization of the view of nuclear waste as danger, to the present view of a grave and implacable hazard to human health and to the natural environment that cannot be entitled to a physical presence.

In other words, the current public understanding of nuclear waste neither just appeared out of the blue at a specific point in time, as it is sometimes assumed, nor had at its start the same shape in which it is encountered today. In addition, though the conceptualization of residues from the exploitation of nuclear reactions took shape at the same time that the American public grew aware of the devastation that followed the atomic bombing in Japan, the data investigated here show that nuclear waste was initially viewed as a peacetime concern and in contrast to military concerns: tellingly, the very introduction of nuclear waste into public discourse appealed for public attention in the context of the war having ended. Finally, though this research cannot directly assess the proposition that nuclear fear is rooted deeply in the human psyche, the data investigated here show that nuclear waste was not always feared in the same seemingly implacable way in which it appears to be feared at present. Instead, to draw a metaphor from the context of nuclear reactions, it was between the years 1945 and 1969 that the nucleus of danger in the public view of nuclear waste exploded, and then, as the awareness of the hazard that nuclear waste presents to human health and to the environment mushroomed, the physical space for disposing of nuclear waste imploded.

\section{Endnotes}

${ }^{1}$ Early in the year 2010, President Obama requested the formation of a commission "to conduct a comprehensive review of policies for managing the back end of the nuclear fuel cycle," known as the Blue Ribbon Commission on America's Nuclear Future, or BRC. The quotation is the very heading of the executive summary of the BRC's final report [2].

${ }^{2}$ In its 2012 report, the Blue Ribbon Commission cited 75,000 metric tons as the nation's then-total inventory waiting for permanent disposal [2]. According to the $\mathrm{Nu}$ clear Energy Institute, or NEI, the current inventory of high-level waste and spent nuclear fuel that are the byproduct of the nuclear energy industry is 71,780 metric tons [15]. One metric ton is equal to approximately $2200 \mathrm{lb}$.

${ }^{3}$ These figures do not include low-level radioactive waste such as from healthcare and other sources.

${ }^{4}$ For example, plutonium, a form of transuranic waste, has a half-life of 24,000 years, meaning that half of the original amount remains radioactive after 24,000 years [16].

${ }^{5}$ It is stored at well over 100 commercial nuclear reactor sites where the waste was generated, including sites of reactors no longer in operation, as well as at over 200 sites managed by the Department of Energy, or DOE. 
${ }^{6}$ “[M] any [commercial] nuclear plants have run out of pool storage capacity," according to the NEI. "At these plants, used fuel is stored above ground" [17]. The storage arrangements for what is known as "defense waste" are described by an observer as "aging tanks larger than most state capitol domes" some of which "threaten groundwater and waterways" [18].

${ }^{7}$ The NEI [19] and the BRC [2] cite the range in metric tons: 2000 to 2300 metric tons per year.

${ }^{8}$ There is a need, even before attempting a taxonomy of these explanations for the origins of the public conceptualization of nuclear waste, to note that the key concepts driving this research (concepts such as "public understanding" and even "the public" itself, or concepts such as "discourse" and "evolution") are not universally self-explanatory but demand, as one peer reviewer put it, conceptual and theoretical clarifications. Acknowledging that concepts of this order have long been at the center of debates of a philosophical nature in sociology, political science, cultural studies, etc. $[20,21]$, this present paper does not side with or dispute any specific theoretical position, nor does it aim to contribute to such debates. Instead, it uses "public," "discourse," and "public discourse" heuristically, for the purposes of the research effort outlined. The author acknowledges that familiarity with the theoretical contexts in which such concepts are usually debated may aid a reader of the paper in better contextualizing the empirical and interpretive findings and conclusions presented here.

${ }^{9} \mathrm{~A}$ body of writing exists in anthropology on the complex legacies of nuclear weapons testing [22].

${ }^{10}$ Responding to peer review commentary, the author recognizes that this route is but one of the possible routes for undertaking this investigation. Indeed, other methodological perspectives exist, rooted in a range of scholarly disciplines, that also promise to help illuminate the important institutional and political forces, as well as the significant historical events that helped shape the public conceptualizations of nuclear waste we encounter in the U.S. at present $[23,24]$. Moreover, as this project's approach may emphasize "the American perspective," perhaps by the very nature of its topical focus, the author acknowledges that the evolution of the public conceptualization of nuclear waste, including that within the U.S. that is the focus of this study, would owe also to other perspectives that originated and developed outside of the U.S. In addition, nuclear waste policy and its history, both within the U.S. and internationally, are subjects of substantial bodies of scholarly writing that conceptualize nuclear waste from a range of angles, including particular sites [25], the siting process as such [26], comparative international perspectives [27], and more.
${ }^{11}$ Pajo J (n.d.) The Two Waves of Public Discourse on Nuclear Waste in the U.S. since 1945.

${ }^{12}$ The ways in which a broad range of forces outside of the media are related to the rise of public conceptualizations may themselves pose questions that may be simply too numerous and complex to be sufficiently addressed within the frame of a research paper such as this one. Responding to peer review commentary, the author acknowledges the importance to this paper's topic of such complex relationships between "institutional forces," "elite groups," "military-industrial," "international actors," and others.

${ }^{13}$ Following the recommendation of one of the journal's peer reviewers, the author experimented with broadening this pool of sampling keywords as follows: one additional search was run in which the keywords "radiation," "fission," and "fusion" were searched in combination with the keyword "waste;" another additional search was run in which the keywords "pollution," "emissions," and "runoff" were searched instead of the keyword "waste." The rationale for this effort was to see whether the initial sample would be thus augmented substantially. The sample could indeed be augmented, but by a total of only 12 additional items. These were triggered as follows: the keyword "pollution" produced seven additional items, the keyword "radiation" produced four additional items, and the keyword "emissions" produced one additional item. The keywords "fission," "fusion," and "runoff" did not pull any additional items from the database. Of the 12 items, two were simply reports of overseas sentiments regarding testing. Reading all 12 items triggered through this subsequent sampling effort appeared to support the interpretations presented in this paper. However, given that these 12 items were not part of the original sample, they are not discussed here at length.

${ }^{14}$ Four of the 77 records that were selected by the electronic database based on these criteria were later excluded from the sample due to the fact that, despite containing valid combinations of the selective keywords, they were topically not about nuclear waste: the keyword "waste" was in those cases used in its "misspending" connotation.

${ }^{15}$ The only exception to the absence of denial of the harms of nuclear waste during these years lies with one single record, which was retained in the sample despite not being directly about nuclear waste. On July 31, 1955, on the occasion of the tenth anniversary of the bombing of Hiroshima, Robert Trumbull, head of the New York Times bureau in Tokyo, wrote: "the stories of how the A-bomb killed the soil, so that plants will not grow in it, are false. Trees are green wherever they stand, some in 'ground zero' of the big blast. If one makes the trip through a bewildering maze of alleys to where the 
medieval Hiroshima Castle stood in architectural beauty until the big explosion, the foundations that are left will be found covered with greenery." Further on, the article targeted the human health topic directly: "according to scientific analyses, the emission of deadly gamma rays and neutrons in the atomic blast over [Hiroshima caused much less human damage than the force and heat released. As for the 'after-effects' of radiation, it is calculated on the basis of careful observation that those who survive the initial impact of such an explosion have a pretty good chance of living a normal life thereafter."

${ }^{16}$ This nicely illustrates the validity of Mary Douglas's classical paradigm of pollution and danger: danger is very great indeed when such matter-out-of-place as nuclear waste enters some place where it especially does not belong and which especially matters: the human body [28].

\section{Competing interests}

The author declares that she has no competing interests.

\section{Authors' contributions}

The author prepared the manuscript. The author read and approved the final manuscript.

\section{Authors' information}

The author is Assistant Professor of Anthropology at Pace University.

\section{Acknowledgements}

The author would like to thank Dagmar Fiedler, Editorial Manager, and the two anonymous reviewers at Environment, Sustainability and Society for helpful and insightful commentaries. The author also acknowledges a Summer 2014 Faculty Research Grant from Dyson College, Pace University that helped write this paper and thanks Maria lacullo-Bird for commentary on the research. A Visiting Scholarship at the New York University Center for European and Mediterranean Studies and the resources of the Bobst Library were also of help. At NYU, Larry Wolff fostered the intellectual environment that inspired the author to explore historically. Finally, the author thanks Erind Pajo for engaging commentary throughout the process.

Received: 8 April 2015 Accepted: 23 November 2015

Published online: 14 December 2015

\section{References}

1. NYT (1950) Atomic 'Cemetery' needed for waste. New York Times. Washington, DC. 29 Jul 1950: p. 15

2. BRC (2012) Report to the secretary of energy. Blue Ribbon Commission on America's Nuclear Future., http://energy.gov/sites/prod/files/2013/04/f0/brc_ finalreport_jan2012.pdf 5 Oct 2015

3. Rudig W (1990) Anti-nuclear movements: a world survey of opposition to nuclear energy. Harlow, Longman

4. Karapin R (2009) On his book Protest Politics in Germany: Movements on the Left and Right since the 1960s. Rorotoko., 15 Jul 2009 http://rorotoko. com/interview/20090715_karapin_roger_protest_politics_germany_ movements_left_right/ 5 Oct 2015

5. Hughes M (2012) Reason, emotion, pressure, violence: modes of demonstration as conceptions of political citizenship in 1960s West Germany. Ger Hist 30(2):222-246

6. UNESCO (2012) The legacy of Rachel Carson's Silent Spring. United Nations Educational, Scientific and Cultural Organization., http://www.unesco.org/ new/en/natural-sciences/ioc-oceans/about-us/special-events/the-legacy-ofrachel-carsons-silent-spring/ Accessed 22 Aug 2014

7. EPA (2014) EPA history: Earth day. Environmental Protection Agency., http:// www2.epa.gov/aboutepa/epa-history-earth-day Accessed 2 Mar 2015

8. Mahaffey J (2010) Atomic awakening: a new look at the history and future of nuclear power. Pegasus, New York
9. Mahaffey J (2014) Atomic accident: a history of nuclear meltdowns and disasters. Pegasus, New York

10. Weart SR (1988) Nuclear fear: a history of images. Harvard University Press, Cambridge

11. Weart SR (2012) The rise of nuclear fear. Harvard University Press, Cambridge

12. Wolf ER (1982) Europe and the people without history. University of California Press, Berkeley

13. Davenport JS (1949) Newspaper circulation: backbone of the industry. W MC Brown Company, Dubuque

14. Bogart $L$ (1989) Press and public: who reads what, when, where and why in American newspapers, 2nd edn. Lawrence Erlbaum Associates, Hillsdale

15. NEI (2014) On-site storage of nuclear waste. Nuclear Energy Institute., http:// www.nei.org/Knowledge-Center/Nuclear-Statistics/On-Site-Storage-of-NuclearWaste Accessed 15 Aug 2014

16. EPA (2014) Transuranic radioactive waste. Environmental Protection Agency., http://www.epa.gov/radiation/docs/radwaste/402-k-94-001-tru.html\#source Accessed 20 Aug 2014

17. NEl (2014) Used nuclear fuel storage. Nuclear Energy Institute., http://www. nei.org/Issues-Policy/Nuclear-Waste-Management/Used-Nuclear-Fuel-Storage Accessed 18 Aug 2014

18. Alvarez R (2014) A primer: military nuclear wastes in the United States. Bulletin of the Atomic Scientists., 24 Feb 2014 http://thebulletin.org/primer-militarynuclear-wastes-united-states 5 Oct 2015

19. NEI (2014) Fact sheets. Nuclear Energy Institute., http://www.nei.org/MasterDocument-Folder/Backgrounders/Fact-Sheets/Safely-Managing-UsedNuclear-Fuel Accessed 22 Aug 2014

20. Habermas J (1991) The structural transformation of the public sphere: an inquiry into a category of bourgeois society (trans: Burger T). The MIT Press, Cambridge

21. Habermas J (1985) The theory of communicative action (Volume 1): reason and the rationalization of society (trans: McCarthy T). Beacon, Boston

22. Johnston BR (ed) (2007) Half-lives and half-truths: confronting the radioactive legacies of the cold war. School for Advanced Research Press, Santa Fe

23. Stewart RB (2011) Fuel cycle to nowhere: U.S. law and policy on nuclear waste. Vanderbilt University Press, Nashville

24. de la Bruheze AAA (1992) Political construction of technology: nuclear waste disposal in the United States, 1945-1972, Dissertation, Universiteit Twente

25. Ringius $L$ (2001) Radioactive waste disposal at sea: public ideas, transnational policy entrepreneurs, and environmental regimes. The MIT Press, Cambridge

26. Jacob G (1990) Site unseen: the politics of siting a nuclear waste repository. University of Pittsburgh Press, Pittsburgh

27. Berkhout F (1991) Radioactive waste: politics and technology. Routledge, London

28. Douglas M (1966) Purity and danger: an analysis of the concepts of pollution and taboo. Routledge \& Kegan Paul, London

\section{Submit your manuscript to a SpringerOpen ${ }^{\odot}$ journal and benefit from:}

- Convenient online submission

Rigorous peer review

- Immediate publication on acceptance

- Open access: articles freely available online

- High visibility within the field

- Retaining the copyright to your article

Submit your next manuscript at $>$ springeropen.com 